\title{
MULTICHIP MODULE TECHNOLOGIES AND ALTERNATIVES:
}

\section{THE BASICS}




\section{Cover Photo}

Courtesy of Unisys photographer, Paul Robinson. The top MCM is a hermetic processor module utilizing the latest MCM-D technology with fine pitch, high lead count, flip TAB connections. The bottom three packages are MCM-C modules with conventional wire bond connections. These modules are described in Chapter 14. 


\title{
MULTICHIP MODULE TECHNOLOGIES AND ALTERNATIVES:
}

\section{THE BASICS}

\author{
Edited by: \\ Daryl Ann Doane \\ Paul D. Franzon
}


Copyright $\odot 1993$ by Springer Science+Business Media New York

Originally published by Van Nostrand Reinhold in 1993

Softcover reprint of the hardcover 1st edition 1993

Library of Congress Catalog Card Number 92-2779

ISBN 978-0-442-01236-6

All rights reserved. No part of this work covered by the copyright hereon may be reproduced or used in any form by any means-graphic, electronic, or mechanical, including photocopying, recording, taping, or information storage and retrieval systems-without written permission of the publisher.

I.TP Van Nostrand Reinhhold is a division of International Thomson Publishing. ITP logo is a trademark under license.

1615141312111098765432

Library of Congress Cataloging-in-Publication Data

Multichip module technologies and alternatives : the basics / [edited] by Daryl Ann Doane and Paul D. Franzon.

p. $\mathrm{cm}$.

Includes Index.

ISBN 978-0-442-01236-6 ISBN 978-1-4615-3100-5 (eBook)

DOI 10.1007/978-1-4615-3100-5

1. Microelectronic packaging. 2. Integrated circuits - Very large scale integration - Design and construction. I. Doane, Daryl Ann. II. Franzon, Paul D. TK7874.M864 1993

621.39 ' $5-\mathrm{dc} 20$ 


\section{DEDICATION}

This book is dedicated with sincere gratitude

to the 42 authors who contributed their knowledge,

suggestions and many hours of writing

to form the chapters we requested.

Without their diligence, timeliness of response and patience with our requests

for additional or alternative information, there would be no book. 


\section{ABOUT THE EDITORS}

Daryl Ann Doane, President, DAD Technologies, Inc., is a specialist in the manufacturing of IC devices and packages, and in the marketing of materials, equipment and processes for such manufacturing. She has published more than 40 reports, papers and reviews documenting new process development and yield optimization. DAD Technologies, Inc. is a technology-based consulting organization serving both producers and users. Clients have included both government and commercial organizations connected with IC fabrication and packaging.

Dr. Doane previously served as Director, Microelectronics R\&D for Hunt Chemical (now Olin Hunt Specialty Products). Prior to that she was a Member of the Technical Staffs of AT\&T Bell Laboratories, RCA and Hewlett-Packard Laboratories.

Dr. Doane is a member of the American Physical Society (APS), Materials Research Society (MRS), International Society for Hybrid Microelectronics (ISHM), International Electronics Packaging Society (IEPS), and is a Senior Member of the IEEE. She received the 1980 Distinguished New Engineer Award from the Society of Women Engineers. She also served as President of the New Jersey Section of that Society. 
Dr. Doane presently serves as Director of Technical Marketing for the IEEECHMT (Components, Hybrids \& Manufacturing Technology) Society. She also is an elected member of the Board of Governors of the National CHMT Society. She served previously as Chairman of the San Diego Chapter of the CHMT Society.

Dr. Doane received the BA with Distinction in Chemistry and Physics, an MA in Chemistry, and an MS and PhD in Metallurgy and Materials Science from M.I.T. and the University of Pennsylvania, respectively.

Paul D. Franzon is currently an Assistant Professor in the Department of Electrical and Computer Engineering at North Carolina State University. He has over eight years experience in electronic systems design and design methodology research and development. During that time, in addition to his current position, he has worked at AT\&T Bell Laboratories in Holmdel NJ, at the Australian Defense Science and Technology Organization, as a founding member of a successful Australian technology start-up company, and as a consultant to industry, including positions on Technical Advisory Boards.

Dr. Franzon's current research interests include design sciences/methodology for high speed packaging and interconnections systems and also for high speed and low power chip design. In the past, he has worked on problems and projects in wafer scale integration, IC yield modeling, VLSI chip design and communications systems design. He has published over 45 articles and reports.

His teaching interests focus on microelectronic systems building including package and interconnection design, circuit design, processor design and the gaining of hands-on systems experience for students.

Dr. Franzon is a member of the IEEE, ACM and ISHM. He serves as the Chairman of the Education Committee for the National IEEE-CHMT Society.

Dr. Franzon received a BS in Physics and Mathematics, a BE with First Class Honors in Electrical Engineering and $\mathrm{ahD}$ in Electrical Engineering all from the University of Adelaide, Adelaide, Australia. 


\section{TABLE OF CONTENTS}

Foreword xxiii

Preface $x x v$

Acknowledgments $\quad x x x i$

Part A: The Framework 1

1 Introduction $\quad 3$

1.1 Background and Definitions 3

1.1.1 Purpose and Perspective of the Book 3

1.1.2 Architecture - Building a

Multichip Module Structure 5

1.1.3 First Level Connection and Common

Circuit Base Alternatives $\quad 9$

1.1.4 MCM Packaging Alternatives 11

1.2 Finding Your Way 15

1.3 The Importance of Materials 17

1.4 The Importance of Manufacturing Processes 21

1.5 The Importance of Industry Infrastructure 22 
1.6 Decision-Making as a Process 25

1.6.1 Determining the Application:

Possible MCM Markets 26

1.6.2 Determining the MCM Technology:

Business Decisions 28

1.6.3 Designing the Product:

Multidisciplinary Engineering $\quad 30$

1.7 Overall Prospects for MCMs 30

$\begin{array}{lll}1.8 \text { Summary } & 32\end{array}$

General References 33

References $\quad 35$

2 MCM Package Selection:

A Materials and Manufacturing Perspective 37

$\begin{array}{ll}2.1 \text { Introduction } & 37\end{array}$

2.2 Package Body and Substrate Base Choices 40

2.2.1 Ceramics $\quad 40$

2.2.2 Organic Laminates 43

2.2.3 Metals 43

2.3 Signal Interconnect and MCM Substrate Choices 43

2.3.1 MCM-C (Cofired Ceramics)

2.3.2 MCM-L (Organic Laminates) 48

2.3.3 MCM-D (Deposited Dielectric) 51

2.3.4 MCM-D/C (Deposited Dielectric
on Cofired Ceramic)

2.3.5 MCM-Si (Inorganic Thin Film) 54

2.3.6 Thick Film Hybrid MCM 55

2.4 Chip Mounting Choices $\quad 56$

2.4.1 Die Attach/Wire Bond 58

$\begin{array}{ll}2.4 .2 \mathrm{TAB} & 60\end{array}$

2.4.3 Flip TAB 63

2.4.4 Flip Chip 63

2.5 Module Level Connection Choices 66

2.5.1 Peripheral I/O 66

2.5.2 Pin Grid Array 67

2.5.3 Pad Array Carrier (PAC) 68

2.6 Global Materials and Manufacturing Considerations 69

$\begin{array}{ll}\text { 2.6.1 Cost } & 69\end{array}$

2.6.2 Electrical Performance $\quad 70$

2.6.3 Thermal Path $\quad 75$

$\begin{array}{ll}\text { 2.6.4 Rework } & 76\end{array}$ 
2.7 Module Design Examples 76

2.7.1 Mainframe Computer Module $\quad 76$

2.7.2 Workstation Module $\quad 77$

$\begin{array}{ll}\text { 2.7.3 Low Cost Module } & 78\end{array}$

2.7.4 Data Communications Module 78

2.8 Future Trends in MCM Materials Manufacturing 81

$\begin{array}{ll}2.8 .1 \text { Substrates } & 82\end{array}$

2.8.2 Optical Multichip Modules (MCM-O) 83

2.8.3 Test $\quad 83$

2.8.4 Thermal Control $\quad 83$

2.8.5 Environmental Concerns $\quad 84$

References $\quad 85$

3 MCM Package Selection: A Systems Need Perspective 87

$\begin{array}{ll}3.1 \text { Introduction } & 87\end{array}$

3.2 System Design Process 88

3.3 The Packaging Hierarchy 90

3.4 Packaging Performance Factors 93

3.4.1 Size and Weight 93

3.4.2 Interconnection Capacity Within Each Level 94

3.4.3 Connection Capacity Between Packaging Levels 100

$\begin{array}{ll}\text { 3.4.4 Delay and Electrical Noise } & 102\end{array}$

3.4.5 Power Consumption 107

$\begin{array}{ll}\text { 3.4.6 Heat Dissipation } & 109\end{array}$

3.4.7 Performance Tradeoffs 111

3.5 Packaging Cost Factors $\quad 112$

3.5.1 Production Cost 112

3.5.2 Post Production Costs 117

3.5.3 Design and Prototyping Costs 118

$\begin{array}{ll}\text { 3.5.4 Time-to-Market } & 119\end{array}$

3.5.5 Cost Tradeoffs 120

3.6 Packaging Decisions and the System Design Process 120

3.7 Determining System Requirements and Goals 121

3.8 Determining and Evaluating Packaging Alternatives 123

3.9 Impact of Semiconductor Technology 124

3.10 Example of the System Design Process 124

3.11 Summary 128

References 130 
4 MCM Package Selection: Cost Issues 133

4.1 Introduction 133

4.1.1 The Importance of Cost 134

4.2 Techniques for Cost Analysis 135

4.2.1 Traditional Cost Analysis 135

4.2.2 Activity-Based Cost Analysis 137

4.2.3 Technical Cost Modeling 138

4.3 Technical Cost Modeling 139

4.3.1 Principles of Technical Cost Modeling 139

4.3.2 Applications of Technical Cost Modeling 141

4.4 Results of Technical Cost Modeling 143

4.4.1 Printed Wiring Boards 143

4.4.2 Thick Film Substrates $\quad 146$

4.4.3 Cofired Multilayer Substrates 148

4.4.4 Thin Film MCMs 150

4.4.5 Cost of MCM Assembly 151

4.5 Applications to Substrate Selection 153

4.6 Design Activity-Based Cost Modeling 157

4.7 Summary 161

References 163

$\begin{array}{ll}\text { Part B: The Basics } & 165\end{array}$

5 Laminate-Based Technologies for Multichip Modules 169

$\begin{array}{ll}5.1 \text { Introduction } & 169\end{array}$

5.1.1 MCM-L Amid the Spectrum of MCM Substrate Technologies $\quad 170$

5.1.2 MCM-L Attributes 171

5.2 Standard MCM-L Construction Process 172

$\begin{array}{ll}\text { 5.2.1 Dielectric Material } & 174\end{array}$

5.2.2 Copper Foil (Conductor) Processing 174

5.2.3 Inner Layer Photolithographic Processing 174

5.2.4 Blind and Buried Via Formation 175

5.2.5 Lamination $\quad 176$

5.2.6 Drilling 176

5.2.7 Plating of Drilled Holes 178

5.2.8 Processing of Surface Layers 178

5.3 Material Considerations 180

5.3.1 Dielectric Layers 181

5.3.2 Polymers for Dielectric Layers 185

5.3.3 Reinforcements for Dielectric Layers 186 
5.3.4 Copper Conductors 186

5.4 Flexible ("Flex") Circuits 187

5.4.1 Flex Circuit and Connector Integration 188

5.5 Advanced MCM-L Material and Process Technology 189

5.5.1 Integral Termination Resistor Technology 189

5.5.2 Additive Conductor Processing 190

5.5.3 Advanced Reinforcement, Rigidifying Materials 192

5.6 IC Connection and Repair: Laminate Implications 195

5.6.1 Wire Bonding to MCM-L Substrates 196

5.6.2 TAB Bonding on MCM-L Substrates 197

5.6.3 Flip Chip Bonding on MCM-L Substrates 197

5.7 Versions of Assembled MCM-L Systems 198

5.7.1 Substrate I/O Configurations 198

5.8 MCM-L Extendibility and Cost Issues 209

References 211

6 Thick Film and Ceramic Technologies

for Hybrid Multichip Modules 215

6.1 Introduction 215

6.1.1 Definitions of MCM-C Technologies 215

6.1.2 General Comparison of MCM-C Technologies 219

6.2 Material Considerations 225

6.2.1 Thick Film Technology 225

6.2.2 High Temperature Cofired Ceramic Technology 234

6.2.3 Low Temperature Cofired Ceramic Technology 235

$\begin{array}{ll}6.3 \text { Processing } & 240\end{array}$

6.3.1 Thick Films 240

6.3.2 High Temperature Cofired Ceramics 242

6.3.3 Low Temperature Cofired Ceramics 243

6.4 Design Rules 244

6.5 Applications $\quad 245$

6.6 Future Trends 248

6.7 Engineering Choices 251

References 253

7 Thin Film Multilayer Interconnection

Technologies for Multichip Modules 255

7.1 Introduction 255

7.2 Characteristics, Benefits of TFML Interconnections 256

7.2.1 Packaging Structures Using

TFML Interconnections 
7.2.2 Signal Line Characteristics 259

7.2.3 Interconnect Design Rules 262

7.2.4 Comparison With Alternative

Interconnection Technologies 264

7.3 Materials for Thin Film Interconnection Systems 267

$\begin{array}{ll}\text { 7.3.1 Substrate Materials } & 267\end{array}$

$\begin{array}{ll}\text { 7.3.2 Conductor Materials } & 272\end{array}$

$\begin{array}{ll}\text { 7.3.3 Dielectric Materials } & 274\end{array}$

7.4 Thin Film Multilayer Processing 276

7.4.1 Conductor Deposition and Patterning Processes 277

7.4.2 Dielectric Deposition and Patterning Processes 282

7.4.3 Basic Process Approaches: Additive and Subtractive 289

7.4.4 Unique Process Requirements 294

7.5 Design Strategies for Thin Film Interconnections 298

7.5.1. General Design Strategies 298

7.5.2 Implementations of Thin Film Interconnections 300

7.6 Applications, Growth of Thin Film Interconnections 304

7.6.1 Interconnection Technology Selection 304

7.6.2 Evolution of TFML Applications 305

7.6.3 Future Applications 306

References $\quad 307$

8 Selection Criteria For Multichip Module Dielectrics 311

8.1 Introduction 311

8.2 Behavior and Function of Dielectrics 312

8.3 Multilevel Thin Film Structures $\quad 314$

$\begin{array}{ll}\text { 8.3.1 Major Technical Challenges } & 314\end{array}$

8.3.2 MCM Fabrication Processes 316

8.3.3 Dielectric Processing 318

8.4 Polymer Properties 319

$\begin{array}{ll}\text { 8.4.1 Some Polymer Specific Terms } & 319\end{array}$

$\begin{array}{ll}\text { 8.4.2 Dielectric Constant } & 320\end{array}$

8.4.3 Thermal Stability 321

8.4.4 The Glass Transition Temperature 322

8.4.5 Coefficient of Thermal Expansion 323

8.4.6 Mechanical Properties 326

8.4.7 Failure Mechanisms 329

8.4.8 Chemical Resistance $\quad 331$

8.4.9 Adhesion 332

8.4.10 Water Uptake $\quad 334$

8.4.11 Planarization $\quad 335$

8.4.12 Influence of Curing Conditions 337 
8.5 Polymer Materials 337

$\begin{array}{lll}\text { 8.5.1 Polyimides } & 338\end{array}$

8.5.2 Polyphenylquinoxaline 346

8.5.3 Fluorocarbons $\quad 346$

8.5.4 Benzocyclobutenes $\quad 346$

8.6 Summary 346

References 347

9 Chip-to-Substrate (First Level) Connection

Technology Options 349

9.1 Introduction 349

9.1.1 Chip Connection Technologies 350

9.1.2 Electrical Design 351

9.1.3 Mechanical Design 351

9.1.4 Technology Comparisons $\quad 352$

9.2 Die Bonding and Physical Attachment 354

9.2.1 Die Attach Material Choices 354

9.2.2 Die Attach Processes And Process Control 358

9.2.3 Die Attach Equipment 363

9.2.4 Issues for MCMs 363

9.3 Wire Bonding 368

9.3.1 Wire Bonding Methods and Procedures 368

9.3.2 Wire Bonding Processes and Configurations:

Geometry, Density and Package Design

Considerations

375

$\begin{array}{ll}\text { 9.3.3 Wire Bonding Equipment } & 379\end{array}$

9.3.4 Electrical Performance 384

9.3.5 Reliability as Applied to MCMs 385

9.3.6 Yield and Repairability as Applied to MCMs 386

9.3.7 Wire Bond Process Development 387

9.3.8 Wire Bond Process Costs 389

9.3.9 Comparison to Other Connection Techniques 391

9.3.10 Summary 392

9.4 Tape Automated Bonding $\quad 394$

9.4.1 Introduction 394

9.4.2 Basic Process Flow for TAB Packaging 396

9.4.3 TAB Tape Considerations 401

9.4.4 Inner Lead Bonding 406

9.4.5 Outer Lead Bonding 410

9.4.6 Single Chip and MCM Implementations of TAB 416

9.4.7 Thermal and Electrical Performance 418 
$\begin{array}{ll}\text { 9.4.8 Reliability } & 420\end{array}$

9.4.9 Reworkability $\quad 423$

9.4.10 Manufacturing Issues and Costs $\quad 425$

9.4.11 Comparison with Other Connection Technologies 427

9.4.12 Summary $\quad 428$

9.5 Flip Chip Connection Technology $\quad 429$

9.5.1 Introduction $\quad 429$

9.5.2 The Basics 429

9.5.3 Connection Medium (I): Solder Bumps 434

9.5.4 Connection Medium (II): Conductive Polymers 446

9.5.5 The Whole Picture 448

9.6 Flip Chip Solder Bump (FCSB) Technology:

An Example $\quad 450$

9.6.1 Introduction $\quad 450$

9.6.2 Fabrication, Process Flow, Tools and Hardware 451

9.6.3 Manufacturability 457

$\begin{array}{lr}\text { 9.6.4 Rework } & 459\end{array}$

9.6.5 Reliability $\quad 462$

$\begin{array}{ll}\text { 9.6.6 Performance } & 473\end{array}$

9.6.7 Summary 476

9.7 Summary $\quad 477$

9.7.1 Cost 477

9.7.2 Performance 478

9.7.3 Tradeoffs: Making a Choice $\quad 480$

References 481

10 MCM-to-Printed Wiring Board (Second Level) Connection Technology Options $\quad 487$

10.1 Introduction 487

10.1.1 Second Level Connection Alternatives 488

10.2 Basic Issues Affecting Connection Choice 491

10.2.1 Mechanical and Materials Issues with

Permanent Soldered Connections 491

10.2.2 Separable Connector Interface Physics 492

10.2.3 Electrical Performance Issues 497

10.3 Basic Approaches to MCM Level Two Connections 499

10.3.1 Direct Attachment Through Soldering 500

10.3.2 Chip-on-Board Connections 502

10.3.3 Separable Connections (Sockets) 502

10.3.4 Sockets for Leadless MCM Substrates 503

10.3.5 Sockets for Leaded MCM Substrates 513 
10.4 Standards Activities 518

10.4.1 Supporting Groups for Standards $\quad 520$

10.5 Summary 521

10.5.1 Recommendations $\quad 521$

10.5.2 Future Trends $\quad 521$

References $\quad 522$

11 Electrical Design of Digital Multichip Modules 525

11.1 Introduction $\quad 525$

11.2 Delay and Noise in Digital Design 526

11.3 Propagation Delay and Reflection Noise 531

11.3.1 Reflections $\quad 540$

11.3.2 Line Losses 541

11.3.3 First Incidence Switching $\quad 546$

11.3.4 Net Topology 549

11.3.5 Effect of Loading $\quad 550$

11.4 Crosstalk Noise 551

11.5 Simultaneous Switching Noise 555

11.6 Other Sources of Noise $\quad 560$

11.7 The Electrical Design Process 561

11.7.1 Technology Selection and System Planning 561

11.7.2 Modeling, Simulation, and MCM Layout 564

11.8 Summary $\quad 565$

References $\quad 567$

12 Thermal Design Considerations for

Multichip Module Applications $\quad \mathbf{5 6 9}$

12.1 Introduction $\quad 569$

12.2 Thermal Management $\quad 570$

12.2.1 Objectives in Thermal Management 570

12.2.2 Thermal Paths 571

12.3 Thermal Phenomena in Electronic Enclosures 571

12.3.1 Heat Transfer Mechanisms 572

12.3.2 Heat Transfer in Electronic Components (Modules) 575

12.3.3 The Concept of Thermal Resistance 577

12.3.4 Heat Transfer On a Board 580

12.3.5 Thermal Coupling in Electronic Enclosures 581

12.4 Thermal Management of MCMs 583

12.4.1 Alternate Thermal Control Methods for MCMs 583

12.4.2 Cooling Methods - Cost Impact of

Thermal Management Techniques 592

12.4.3 Parameters Impacting MCM Thermal Performance 593 
12.5 Tools for Thermal Design 595

12.5.1 Overview of Design Analysis Tools 595

12.5.2 Analysis Tools 596

12.5.3 Solution Procedure 598

12.5.4 Analytical Modeling - Integral Method 598

12.5.5 Computer Based Tools - Numerical Method 604

12.5.6 Experimentation - Why, When and How 607

$\begin{array}{ll}12.6 \text { Summary } & 610\end{array}$

References 611

13 Electrical Testing of Multichip Modules 615

13.1 Introduction 615

13.2 Substrate Test 616

13.2.1 Introduction 616

13.2.2 Fixed Probe Array Testing 619

13.2.3 Single Probe Testing 621

13.2.4 Two Probe Testing 625

13.2.5 Electron Beam Probing 628

13.2.6 Developing a Substrate Test Strategy 630

13.2.7 Summary 630

13.3 IC Test 631

13.3.1 Requirements for MCM Modules 631

13.3.2 Introduction to IC Test 632

13.3.3 Test Generation 633

13.3.4 Boundary Scan and Built-In Self Test 634

$\begin{array}{ll}\text { 13.3.5 Parametric Testing } & 637\end{array}$

13.3.6 Wafer Probing 638

13.3.7 Die Carriers and Packages $\quad 638$

13.3.8 Final Test $\quad 640$

13.3.9 Burn-In 641

13.3.10 Summary 644

13.4 Assembled Module Test 644

13.4.1 Introduction 644

13.4.2 Testing Strategies $\quad 645$

13.4.3 Design for Testability $\quad 649$

13.4.4 Test Generation $\quad 651$

13.4.5 Test Equipment $\quad 654$

$\begin{array}{ll}\text { 13.4.6 Bring-Up } & 655\end{array}$

13.4.7 Production Test 656

13.4.8 Summary $\quad 657$

$\begin{array}{ll}13.5 \text { Conclusion } & 658\end{array}$ 
14 The Development of Unisys Multichip Modules 665

14.1 Introduction

14.2 The Driving Forces Behind Multichip Packaging 666

14.3 Advances in Silicon Delay Multichip Modules 667

14.4 Single Chip Packages have Limitations 668

14.5 Basic Packaging Goals 668

14.6 Multichip Module Development Process 669

14.6.1 Designing Through Technology Change 669

14.6.2 Develop a Multichip Packaging Strategy First 670

14.6.3 Technical Decision Making in an MCM Program 670

14.6.4 Making Multichip Module Tradeoffs in a Disciplined Way 671

14.6.5 Temperature Hierarchy Management 676

14.6.6 Problems Encountered and Solutions Developed 676

14.6.7 Good News for the MCM Developer 678

14.6.8 Verify the Reliability of the Multichip Module 679

14.6.9 Summary of Development Phase Challenges 679

14.7 Unisys Multichip Module Implementations 680

$\begin{array}{ll}\text { 14.7.1 SCAMP } & 680\end{array}$

14.7.2 A16/A19 682

14.7.3 2200/900 Double Sided Multichip Module 683

14.7.4 Limits of Cofired MCMs 685

14.7.5 Thin Film MCMs 686

$\begin{array}{ll}14.8 \text { Multichip Module Industry Issues } & 690\end{array}$

References 693

15 High Performance Aerospace Multichip Module

Technology Development at Hughes $\quad 695$

15.1 MCMs Meet the Needs of Systems Evolution 695

15.1.1 Examples of Trends in Weapons 696

15.1.2 Measuring the Trends 701

15.2 New Packaging Roles 706

15.2.1 A High Density Multichip Interconnection Program 706

15.2.2 A Company Wide Electronics Packaging Program 706

15.3 Developing Two Key MCM Technologies 707

15.3.1 An Evolutionary Approach 708

15.3.2 Technology Comparisons $\quad 709$

15.3.3 HDMI Technology 711

15.3.4 Low Temperature Cofired Ceramic (LTCC) Technology 718 
15.4 Comprehensive Design/Manufacturing Services 721

$\begin{array}{ll}\text { 15.4.1 Design } & 722\end{array}$

15.4.2 Interconnection Structures 727

15.4.3 Pretesting of Packaging System Elements 727

15.4.4 Component Attachment and Connections $\quad 729$

15.4.5 Electrical Testing $\quad 731$

15.4.6 Inspection, Quality and Reliability 732

$\begin{array}{ll}\text { 15.4.7 Encapsulation } & 732\end{array}$

$\begin{array}{lll}15.5 \text { Summary } & 734\end{array}$

References $\quad 734$

16 Silicon-Based Multichip Modules $\quad 737$

$\begin{array}{ll}16.1 \text { Introduction } & 737\end{array}$

16.2 Materials 738

$\begin{array}{ll}\text { 16.2.1 Silicon Substrates } & 738\end{array}$

16.2.2 Conductors $\quad 743$

16.2.3 Dielectrics $\quad 744$

16.3 MCM Examples $\quad 747$

16.3.1 Prototype Silicon Substrates $\quad 748$

16.3.2 Custom Silicon Substrates $\quad 752$

$\begin{array}{ll}16.4 \text { Summary } & 761\end{array}$

References $\quad 766$

17 The Technology and Manufacture of the

$\begin{array}{ll}\text { VAX-9000 Multichip Unit } & \mathbf{7 6 9}\end{array}$

$\begin{array}{ll}17.1 \text { Introduction } & 769\end{array}$

17.2 MCM System Perspective $\quad 770$

17.3 VAX-9000 MCU Development 772

17.3.1 VAX-9000 Performance Goals 772

17.3.2 Analysis of Alternative Physical Technologies 772

17.3.3 VAX-9000 MCU Strategy 773

17.3.4 MCU Manufacturability Goals $\quad 774$

17.3.5 Concurrent MCU Engineering and Manufacturing 774

17.3.6 MCU Quality Engineering $\quad 775$

17.4 VAX-9000 MCU Technology 776

17.4.1 MCU Overview 776

17.4.2 MCU Integrated Circuits 778

17.4.3 HDSC Interconnect Technology $\quad 780$

$\begin{array}{ll}\text { 17.4.4 MCU Structure } & 782\end{array}$

17.4.5 MCU Electrical Characteristics $\quad 784$

$\begin{array}{ll}\text { 17.4.6 MCU Thermal Management } & 785\end{array}$ 
17.4.7 MCU Test Technology 786

17.5 VAX-9000 MCU Manufacturing 795

17.5.1 Overview of Manufacturing Process 795

17.5.2 HDSC Signal Core Fabrication Process 797

17.5.3 HDSC Power Core Fabrication Process $\quad 800$

17.5.4 HDSC Assembly Process $\quad 801$

17.5.5 MCU Subassembly Process $\quad 803$

17.5.6 MCU Assembly Process $\quad 807$

17.6 Future Evolution of MCM Technology 808

17.6.1 Strategy for Migration of MCM Technology

from Mainframe to Low Power Applications 809

$\begin{array}{ll}\text { References } & 813\end{array}$

Part D: Closing the Loop $\quad 815$

18 Complementing Technologies for MCM Success $\quad 817$

$\begin{array}{ll}18.1 \text { Introduction } & 817\end{array}$

18.2 Separable Connectors and the Packaging Hierarchy 818

18.3 Effect of Semiconductor Type on Package Design 824

18.4 System Performance Level (Cycle Time) 826

18.5 Level of Chip Integration, Function Size and Chip I/O 828

18.5.1 Memory MCMs $\quad 828$

18.6 Chip Joining Interface, Burn-in, Testability and Repair $\quad 830$

18.6.1 Known Good Die $\quad 830$

18.6.2 Chip Joining Interface $\quad 831$

18.6.3 Flip TAB $\quad 831$

18.6.4 Flip Chip $\quad 831$

18.7 Power Density and Cooling Methods 832

18.8 Timeliness of Introduction $\quad 834$

18.9 Alternatives to MCMs 834

18.9.1 Future Growth in Single Chip Packaging 836

18.10 Inexpensive, Low Complexity MCMs $\quad 838$

$\begin{array}{ll}18.11 \text { Summary } & 840\end{array}$

$\begin{array}{ll}\text { References } & 840\end{array}$

$\begin{array}{lr}\text { Epilogue } & 843\end{array}$

About the Authors $\quad 845$

Index $\quad 859$ 


\section{FOREWORD}

Far from being the passive containers for semiconductor devices of the past, the packages in today's high performance computers pose numerous challenges in interconnecting, powering, cooling and protecting devices. While semiconductor circuit performance measured in picoseconds continues to improve, computer performance is expected to be in nanoseconds for the rest of this century - a factor of 1000 difference between on-chip and off-chip performance which is attributable to losses associated with the package. Thus the package, which interconnects all the chips to form a particular function such as a central processor, is likely to set the limits on how far computers can evolve.

Multichip packaging, which can relax these limits and also improve the reliability and cost at the systems level, is expected to be the basis of all advanced computers in the future. In addition, since this technology allows chips to be spaced more closely, in less space and with less weight, it has the added advantage of being useful in portable consumer electronics as well as in medical, aerospace, automotive and telecommunications products. The multichip technologies with which these applications can be addressed are many. They range from ceramics to polymer-metal thin films to printed wiring boards for interconnections; flip chip, $\mathrm{TAB}$ or wire bond for chip-to-substrate connections; and air or water cooling for the removal of heat. 
While there are several books now on packaging, these books deal with the subject of multichip modules as part of packaging in general, or they treat a particular multichip module technology or they are at an advanced level. What is needed, therefore, is a comprehensive book at the basic level, structured so that anyone entering the field can quickly learn about the technologies, understand the tradeoffs, review the product examples, and make systems level decisions.

Such a book has been provided by Daryl Ann Doane and Paul D. Franzon. They have worked with an outstanding team of packaging experts from industry and universities. Together they have produced Multichip Module Technologies and Alternatives: The Basics, an outstanding book for both industry and university use. It is equally appropriate as an introduction to the multichip module technologies for those just entering the field, and as an up-to-date basic technical book for those currently practicing in it.

The books deals with the subject of multichip modules along three parts: systems level perspectives including packaging technology options and costs, the basics of ceramic, thin film and printed wiring board technologies as well as chip and module level connections; thermal and electrical design considerations including electrical testing; and finally product examples illustrating how multichip modules have been useful.

The basic and integrated nature of the book clearly reflects the dedication and the hard work of the editors and the authors.

Rao R. Tummala 


\section{PREFACE}

\section{Welcome!}

Welcome to our book. We feel it is a unique book in the field of packaging and we hope you find it both useful and enjoyable. We (editors and authors) have certainly enjoyed bringing it to you!

\section{Uniqueness of the Book}

This is a very unique book! Its uniqueness comes about in two ways: first in the approach to the subject, and second, in the approach to the writing of the book.

First, we feel that this book helps define a turning point in the discipline of packaging. The "bottleneck" to increased systems performance is now more often the package than the chip. One effect of this is that suddenly a whole "breed" of engineers need to gain an understanding of how package design affects their systems performance and cost goals. Another effect is the widespread recognition that multichip module packaging technologies are possible solutions to this performance limitation. The attendant explosive growth in the MCM technology alternatives available is a testimony to this recognition. 
Until recently, packaging was mainly the domain of mechanical and materials specialists, and furthermore was rarely taught at universities. This has changed. Almost overnight, the pressure of high on-chip speeds and high transistor counts meant that packaging became a subject that must be understood by just about any engineer involved in designing a system. When these engineers tried to establish their understanding they found themselves in a virtual "Tower of Babel." First, often the same terms were used for different things or, just as bad, different terms were used for the same thing. Second, as this was the domain of specialists, significant background was required in each discipline in order to understand it. This book turns the discipline of packaging into a subject accessible to the generalist rather than just one accessible to the specialist. Common terms are defined and crosslinked to the terms in current usage. Each discipline is presented in such a way that is both understandable to all and is useful. In providing this book, we help turn packaging into a discipline in which anyone can participate. We also present a book highly suited for teaching within a university.

The book also is unique in how it was created! Packaging is a multidisciplinary subject. We realized that no two people can claim mastery of all the disciplines needed and involved in the subjects we wished to cover. We also realized that rapid writing was important. Thus an edited text was called for. But edited texts are often poorly lacking in terms of understandability and flow. Usually an editor relies on selecting appropriate experts and then accepting what each expert writes with minor alterations.

This book is very different. It could be called a "closely edited" text. Each chapter has had the heavy hand of development of both editors in it. This happened in several forms. Often we spent many hours with individual authors defining what we thought was appropriate and guiding them in the actual writing. In all cases, as well as seeking outside reviewers, we wrote "anonymous" reviews ourselves. In some cases, we directly adjusted the text after it was submitted. Thus we are responsible for the final product as much as each chapter author is.

The result, we feel, is a book that has the authority that comes with a book written by a team of experts, but has the understandability, completeness and flow of a book written by a single author, At least we hope that the book comes as close to that ideal as possible!

\section{Audience}

For whom is the book intended? This book is for everyone! The emphasis in the book is on understanding the fundamentals and the reporting of real 
experiences rather than including a huge amount of data. It is intended for those who need a broad exposure to the concepts underlying the design, fabrication, packaging, assembly, manufacturing of multichip modules and the costs associated with alternative packaging technologies. The book is intended for applications, manufacturing and design engineers as well as for technical decision makers and managers who are confused about MCM issues but who wish to understand the fundamentals and basics. Specifically, it will be useful to

- engineers in design, processing, fabrication, manufacturing, assembly and test who need to choose a packaging technology for specific product and application goals;

- managers determining technology alternatives for new systems needs;

- marketing; sales technologists who need a working knowledge of the alternative MCM technologies.

The book also is a suitable text for advanced undergraduate and graduate students in design, electrical, mechanical and systems engineering as well as for students in the applied sciences as discussed further on in this Preface.

\section{Philosophy of the Book}

What are the key decisions needed when considering using MCM technologies? There are four perspectives: materials, manufacturing, systems performance and cost requirements. The book presents the basics of MCM technologies from these four perspectives with an emphasis on decision-making. How do you choose a packaging technology from a systems performance, cost perspective? What are the fundamental materials and manufacturing issues that need to be considered? Is the packaging strategy appropriate to the design goal?

This book is applications-oriented in the sense that it discusses

- Examples of MCMs and the products and systems in which they have been used,

- Examples of equipment and processes used to design, build and test MCMs,

- Actual case studies and insights provided by leading companies themselves rather than a summary of reported results. 


\section{Organization of the Book}

The book is divided into four parts which we call

- Part A - The Framework

(Making Decisions: The Big Picture)

- Part B - The Basics

- Part C - Case Studies

- Part D - Closing the Loop

Each Part begins with what we call a "frame" in which we summarize the purpose or goals of the Part. The frames alert the reader to what theme dominates in the Part, and what can be learned from it. The frames are set apart from the rest of the book by the border around their pages.

For example, in Part A, the goal is to present a basis for understanding multichip module technology possibilities for packaging. We call this a framework for understanding. The basic definitions needed for understanding are presented. Some alternative packaging approaches are discussed, and the themes of decision-making and the design process that run through the book are also introduced. The reader is alerted to look for the global picture in Part A, an overview that a breadth of knowledge is required for understanding, and that an awareness of the basic concepts introduced is Part A will enable him or her to follow the detailed technical information in Part B.

Part B provides an understanding of the technical fundamentals in the design, fabrication and testing of multichip modules. The tutorials in Part B are unique in the published literature. For example, there is detailed coverage of MCM-L, the fabrication technology based on laminate structures. Another special feature of Part B is the discussion of multichip module-to-printed wiring board (second level) connections in Chapter 10. The test chapter (Chapter 13) provides specific guidelines on how to design MCM products for testing and how to reduce test cost and effort. In each Chapter, the reader is alerted to the options associated with the technologies presented so that these options can be related to product applications.

Part C consists of "reports" from some companies that have created and are selling successful MCM products. The development of their MCM tecinologies, internally from existing expertise, is described. Here the reader will benefit from the insights shared by these companies.

Finally, Part D "closes the loop." It focuses on what aspects of all the technologies presented are likely to have the greatest impact on meeting future needs from a systems perspective. It also presents a forward view by describing 
some open, unsolved problems, open challenges that must be met if future systems are not to be constrained in performance by limitations in packaging technologies.

\section{Use as a Textbook}

We feel that this book is highly usable as a packaging textbook. It covers this interdisciplinary topic at a level that is accessible to all while providing concrete learning material. This book emphasizes decision-making and design, and thus, relates directly to what practicing engineers do for a living. It would be useful in both graduate courses and advanced undergraduate courses. It has the tightness and continuity of a textbook in contrast to a typical edited book. In our opinion, this book is superior to any current packaging "textbook" for use as a text mainly because of the style of presentation.

Despite its title, it could be used for many courses that do not feature only MCMs. Throughout this book, single chip packaging is presented as an alternative to be considered. The design chapters apply equally well to single chip and multichip package design. The only single chip package elements that are missing are a discussion of how plastic packages are made and a specific discussion of how boards are assembled. Chapter 9 covers some of these related points. Board manufacturing is covered in Chapter 5. Single chip ceramic package manufacturing uses similar processes as those for making ceramic MCMs which are discussed in Chapter 6.

There are several types of courses that can use this book. One of us (PDF) uses the book in a semester long graduate course on packaging design for electrical engineers. That course starts with an overview of packaging alternatives (Chapters 1 and 2, with 5 to 10 as references), discusses systems level decision-making (Chapter 3 and parts of the Case Studies), and briefly discusses cost (parts of Chapter 4). Almost half of the course is concerned with electrical design of packaging (Chapter 11). A small amount of time is spent on thermal design (Chapter 12), to the level of detail needed by an electrical engineer, and on the appropriate impact of testing on design (Chapter 13).

The book also would be useful for a more technology and manufacturing oriented course. There Chapters 1 and 2 would be used to introduce the course. Establishing the reasons for the multiple packaging alternatives available and how to choose among them would be covered with the aid of Chapter 3 . Chapter 4 provides a detailed look into the impact of manufacturing costs. Chapters 5 through 10 would be used to teach the bulk of the course. Brief references to Chapters 11 through 13 would provide technologists with an 
understanding of how their decisions affect design. Chapter 17 would offer a detailed manufacturing viewpoint.

Finally, this book also could be useful to mechanical and chemical engineers and materials science-based courses on packaging.

Daryl Ann Doane

Paul D. Franzon 


\section{ACKNOWLEDGMENTS}

With the publication of this book, it is a special pleasure for one of us (DAD) to express gratitude and appreciation to Paul B. Wesling, Tandem Computers. His longstanding and patient role as mentor and resource person has provided an immeasurable educational opportunity and insight regarding the value of technical publications. He currently serves as Vice President of Publications for the IEEE Components, Hybrids and Manufacturing Technology (CHMT) Society. He has been a pioneer in the area of technical publications related to peerreviewed journals, reprint as well as conventional books and Conference Proceedings. His innovative ideas in publications have been adopted by Societies outside of the IEEE, and also are reflected in the value and vision for this book. Thank you, Paul!

Several people advised us on technical and organizational topics. They generously contributed their time and valuable expert knowledge in extended discussions. In particular, Dr. Robert C. Sundahl, Intel, Dr. Walter J. Bertram, Alcoa Electronic Packaging and Professor R. Wayne Johnson, Auburn University, shared their ideas on what was needed in the book, as well as providing detailed reviews for several of the chapters. We wish to thank them.

John H. Lau, Hewlett-Packard was helpful in sharing his experience as an editor of three books for Van Nostrand Reinhold. He never tired of answering questions; we appreciate his patience and helpfulness very much. 
John Nelson, Unisys, is very special! A faithful colleague and friend, he graciously responded positively to so many requests, providing the value of his longstanding experience and insight in the packaging industry in answering questions pertaining to the book. It has been a wonderful opportunity to discuss the technical aspects of the book, as well as its human side, with him. Many of the unique aspects of the book are due to his suggestions. We thank him for everything!

Each chapter in the book was reviewed by at least three individuals whose areas of expertise covered the chapter topic. We also deliberately asked individuals who worked in areas peripheral to a chapter topic to review the chapters for comprehension and clarity. Although we cannot list these more than 54 individuals, we are very appreciative of their efforts, thoroughness and helpful comments. We took them all very seriously.

Still, with all the technical expertise brought to form the contents of this book, there would have been no way to complete a book of this scope, size and complexity had it not been for the unique combinations of dedication and perseverance of the staff and management at Van Nostrand Reinhold (VNR), our publisher. We are very grateful for their efforts. Especially noteworthy was the standard of inspiration set by Mr. Stephen Chapman, Electrical Engineering Editor. He shared our "vision" for the book and persevered on our behalf for the conventional as well as the nonconventional requests we made. He arranged for an accelerated publication schedule so the book could be available when requested. Without his dedication to the book it would not have appeared in such a timely manner.

Sue Alexander of Seaborn Enterprises, Chandler AZ, was responsible for producing the galleys with artwork for the entire book. She demonstrated a high level of skill and innovation in adapting busy tables and complex equations to a text already filled with an unusual amount of photos and artwork. All the while she was faced with unprecedented time constraints. We are very much in awe of the final excellence of her creation in the layout and appearance of the book.

Most of all, we would like to thank those who are close to us. One of us (DAD) wishes to express special thanks to Dr. John L. Doane, Timothy A. ("TAD") Doane and Stevie Doane for their love, support and patience. Their faithful encouragement and sustaining, as well as helpful, assistance contributed significantly to the existence of the book. The other of us (PDF) gives loving thanks to Debra L. Ray in acknowledgment of her forebearance during the many long evenings and weekends when he was not there. 